In a disease such as rheumatoid arthritis, a new treatment must be submitted to a formal clinical trial involving placebo and drugs known to be effective, or else the results obtained may be misleading.

\section{DAVID JAMES}

JANE REEBACK

Department of Rheumatology,

London E1 1BB

${ }^{1}$ McConkey B, Davies P, Crockson RA, et al. Ann Rheum Dis 1979;38:141-4.

Huskisson EC. In: Scott JT, ed. Copeman's textbook of the rheumatic diseases. Edinburgh, Churchill Livingstone, 1978:1009-21.

** We sent these letters to Dr McConkey, whose reply is printed below.-ED, $B M$ F

SIR,-Drs James and Reeback accuse us of ignoring convention. We unrepentantly plead guilty. Whether or not the result will turn out to be misleading will emerge with time. Obviously our confidence in our data, for a lot of reasons, is considerable; otherwise we would not have submitted the paper. Meantime we hope people will give careful thought to sulphasalazine and to conventional (which should not mean sacrosanct) methods for studying the effects of drugs on rheumatoid arthritis.

With regard to the letter by Professor Currey and Dr Chaput de Saintonge, we used, as we said, Student's $t$ test for paired variants. This involves considering changes in values before and after in the same individual. Surely so elementary a point needed no elaboration. There may be a valid argument for using non-parametric tests (for C-reactive protein anyway), but the differences were so large that it hardly seemed worth recalculating the data.

Professor Currey and Dr Chaput de Saintonge raise the issue of dropouts and falling numbers. The principal changes in the ESR and C-reactive values were at 4-10 weeks, when most of the patients were still in the study, and thus bias from this source was negligible. An attempt at simplifying our table (I think I am right in saying after discussions with your editorial staff) appears to have confused them. The original table had one more column, which gave the total number of patients taking the drug at the various times chosen for analysis. As we said, "Patients did not attend at exactly regular intervals, and time points ( \pm 14 days) with the largest number of results were chosen for data analysis." Thus at each time the number taking the drug would exceed the number who attended the clinic. The "sample" at each time \pm 14 days was, so far as we can tell (and we have no desire to get a false result), strictly representative. We agree that falling numbers introduce bias; the issue is often ignored; we reported the facts.

BRIAN MCCONKEY

Rheumatology Division

(Department of Medicine),

Dudley Road Hospital,
Birmingham B18 7QH

\section{Gastroscopic evaluation of anti-} inflammatory agents

SIR,-In their paper on gastroscopic evaluation of anti-inflammatory agents (12 January, p 75), Drs I Caruso and G Bianchi Porro state that "the number of new ulcers develop- ing during this study was extremely low (two out of 249 patients)." But one must first subtract from the 249 patients the 24 patients with scars of old gastric ulcers since they were no longer at risk of getting a "new" ulcer. The incidence during the one year (on the assumption that all patients were actually followed for a full year, a point not made clear in the paper) was two out of 225, giving a rate of 8.9 per 1000 persons per year. Since the incidence of new gastric ulcers in the general population is about 0.31 per 1000 persons per year, ${ }^{1}$ the incidence found in this study is 29 times the expected rate and thus high rather than "extremely low" as they claim. In studies on the ulcerogenic action of antiinflammatory drugs the true annual incidence rates of new cases of gastric ulcers are seldom compared with the appropriate annual incidence rate in the general population.

Since chronic gastric ulcer is probably the most important gastric complication of antiinflammatory drugs and since such ulcers usually occur only in patients who have been taking the drugs for months, ${ }^{2} 3$ it is important that ulcers and erosions are reported separately and not lumped together as "lesions," as Drs Caruso and Bianchi Porro and others ${ }^{4}$ have done. The claims that the many new antiinflammatory drugs introduced in the last few years are less gastrotoxic than aspirin are based almost entirely on short-term studies showing less occult faecal blood loss and fewer gastric erosions. The question of whether any of these agents produces fewer chronic gastric ulcers during long-term administration has not yet been answered. Appropriate studies to answer this question are needed.

M I Grossman

Center for Ulcer Research and Education,

VA Wadsworth Medical Center,

Los Angeles CA 90073, USA

1 Bonnevie O. Scand $\mathcal{f}$ Gastroent 1975;10:231-9.
2 Levy M. New Eng $\mathcal{f}$ Med 1974;290:1158-62.

Silvoso GR, Ivey KJ, Butt JH, et al. Ann Int Med 1979;91:517-20. 1979;91:517-20.
Lanza FL, Royer GL, Nelson RS, et al. Digest Dis Sci
1979;24:823-8.

SIR,-In their detailed paper concerning gastroscopic evaluation of anti-inflammatory drugs (12 January, p 75) Drs I Caruso and G Bianchi Porro consider that antirheumatic treatment should be subject to endoscopic control.

At the most conservative estimate 25 of their 164 patients with rheumatoid arthritis will have some degree of atlantoaxial subluxation, and I consider that the forces on this joint with the neck necessarily held in flexion, under diazepam sedation, during gastroscopy make this a potentially hazardous procedure even in experienced hands. There is not only the risk of acute subluxation but also the more likely possibility of exacerbating preexisting cervical myelopathy, which may cause morbidity not always appreciated by the investigator.

ROGER OLDHAM

Leicester General Hospital, Leicester

\section{Ketotifen in adult asthma}

SIR,-The British Thoracic Association (BTA) study (9 February, p 360) demonstrated small benefit over a four-week period for ketotifen in adult asthma. The onset of action of ketotifen seems to be relatively slow, ${ }^{1}$ and I have been involved in a study of ketotifen in which a longer period of assessment (12 weeks) was used (G R Kennedy and J Munro Sherriff, unpublished observations).

As Craps et $a l^{1}$ and papers presented to the International Congress on Respiratory Disease (Basel, October 1979) showed, over a 12-week period analysis of data on patients shows ketotifen to be comparable in activity to disodium chromoglycate, and individual patients have responded well. This has been achieved at the smaller dose used in the BTA study ( $1 \mathrm{mg}$ twice daily) with a much reduced incidence of side effects, especially drowsiness.

I think it worth while therefore to stress that with the lower dose and in the longer term beneficial effects, without unreasonable side effects, can be achieved in patients with allergic asthma.

J MUNRO SHERRIFF

Caddington, Beds

Craps L, Greenwood C, Radielovic P. Clin Allergy 1978;8:373-82.

SIR,-The recent report by Drs A J Dyson and A D Mackay (9 February, p 360) showed a small reduction in bronchodilator usage after four weeks on ketotifen in asthmatics not receiving inhaled corticosteroids. Most controlled studies published to date have examined only four weeks' administration of ketotifen and a trend towards improved control in atopic subjects has been demonstrated. ${ }^{1}$ There is some evidence of progressive efficacy with a longer course of treatment. The only controlled trial as yet reported, of three months' treatment against placebo in atopic asthmatics, showed a significant reduction in asthma symptom scores and bronchodilator therapy at three months which was not evident by one month; there was also a small but significant improvement in $\mathrm{FEV}_{1}$ and in rhinitis control (Sandoz, data on file, 1979). It would seem that more prolonged trials of ketotifen are required to establish whether its efficacy is more than marginal.

Drs Dyson and Mackay report a $14 \%$ incidence of severe drowsiness and Dr Prowse (1 March 1980, p 646) was forced to withdraw the drug in 14 of 17 subjects. This contrasts markedly with our experience in a trial of 35 patients, in which only one subject was withdrawn because of drowsiness. The overall incidence of side effects in $\mathbf{4 1 3}$ subjects studied by Sandoz in 13 studies submitted to the Committee on Safety of Medicines in July 1979 was $30 \%$, including $12.6 \%$ complaining of drowsiness, with 28 patients $(6.8 \%)$ forced to drop out of the trials. This percentage of side effects was similar to that of patients taking Intal (sodium cromoglycate by inhalation) in comparative studies-namely, $40 \%$, with $6.4 \%$ of drug-related drop outs.

STEPHEN G SPIRO

Brompton Hospital

1 Wells A, Taylor B. Clin Allergy 1979;9:237-40.

\section{Safety of bromocriptine}

SIR,-In a letter by Drs F Lechin and Bertha van der Dijs (16 February, p 480) the statement "Some theoretical concern that bromocriptine may be a teratogen" is made.

We would like to assure your readers, particularly those who are prescribing bromocriptine (Parlodel) for the treatment of amenorrhoea, galactorrhoea, and infertility, 